\title{
EJNSO
}

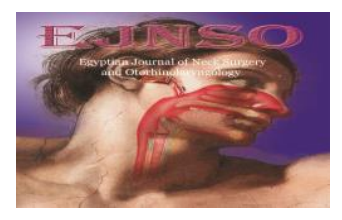

\section{Assessment protocol for Auditory and Language Abilities in Cochlear Implanted Children used in Sohag university hospital}

\author{
El-Adawy A. A.N., Emam A.M., Mostafa E. M., Gelaney A. and Awad H.E. \\ Phoniatrics unit, Otorhinolaryngology Department, Sohag University Hospital, \\ Sohag, Egypt
}

\begin{abstract}
:
Objectives: The aim of this study is to develop Sohag protocol for assessment of auditory and language abilities in patients in patients with cochlear implant in order to provide better management of cases.

Patients and methods: After meticulous revision of the majority of literature pertaining to cochlear implant assessment protocol in children of cochlear implant. We chose 3 main protocols to develop our protocol which are protocol of Ain Shams Phoniatrics Unit (Kotby et al., 1995), Nottingham Early Assessment Package (NEAP)) Nikolopoulos et al., 2005) and EARS test battery (Evaluation of Auditory Responses to Speech) (Esser-Leyding, 2012). We developed a new protocol that suits our patients in the cochlear implantation program. The new protocol was presented and revised by the phoniatricans of Sohag university phoniastrics unit then it was applied on 130 consecutive patients before and after implantation and rehabilitation sessions.
\end{abstract}

Results: The results of the operation were statistically significant reflecting improvement in auditory and language abilities of patients after the operation.

Conclusions: Comparing Sohag Phoniatric unit protocol of assessment with other protocols indicated that our protocol added many significant items needed in the valuation as evaluation of auditory skills, hours of parent participation at home and regularity of sessions.

Key words: Cochlear implant, assessment protocol, auditory skills, children.

\section{$\underline{\text { Introduction }}$}

The advent of multichannel cochlear implant (CI) provided a treatment that would allow severe to profound deaf persons to improve their hearing (Abdollahi et al., 2017). The first CI operation at Sohag University Hospital was done in October 2014 using a MED-EL product. Sohag CI team was established in November 2014 as a university-based center composing of trained surgeons, audiologists, phoniatritians, psychiatrists and radiologists and psychologists with the assistance of medical engineers.

There are many different protocols for assessment of hearing-impaired children around the world like protocols of Ain Shams Phoniatrics Unit and Nottingham Early Assessment Package. The use of adequate assessment instruments in healthcare is crucial for clinical and 
economic management. Several cochlear implantation programs use batteries of tests for that purpose (Vlastarakos et al., 2010). The option for a battery of tests rather than for a single test is explained by the complexity involved in children's developmental assessment. In Egypt, specific assessment tools for hearingimpaired children are scarce. The purpose of this study is to develop a protocol for evaluation of $\mathrm{HI}$ children at Sohag university hospital in order to provide better management of cases.

\section{Patients and Methods:}

The development of the protocol passed into 3 steps:

I. First, we did search and review of the available protocols:

(a) Search for the available wellformed protocols for assessment of Hearing-Impaired children.

(b) Review and discuss suitable protocols for our culture and facility for application by phoniatrics team at Sohag university hospital.

II. Design the protocol by two phoniatricans after evaluation and discussion of the available protocols of assessment.

III. Validity and specificity of the protocol

A. Content validity test: the protocol was revised by 3 expert phoniatricians at Sohag University experienced 7-25 years.

B. Test - retest reliability: the protocol was applied on 130 patients and reapplied after therapy every three month in the first year and every 6 months afterword.

This cross-sectional study took place from December 2014 to December 2017. It included 130 children that have been implanted at Sohag University Hospital (SUH) whose onset of deafness was pre-lingual and continued follow up schedule till 18 months postoperative.

\section{Statistical analysis:}

Descriptive statistical analysis was done, and quantitative data was expressed as means \pm standard deviation. Data was analyzed using SPSS program version 16. A 5\% level was chosen as a level of significance in all statistical tests used in the study. Friedman test for nonparametric data was done to evaluate the progress of the patients.

\section{Results:}

I-Reviewing all available protocols of assessment of HI:

We decided to choose the main three suitable protocols that are aligned with our view and facilities in Sohag phoniatrics unit. All these protocols agree in the main items of its structure. They include patient and parent interview, auditory perceptual assessment, auditory assessment, receptive and expressive language, speech assessment.

We chose 3 main protocols of assessment as following:

\section{1) Ain Shams Phoniatrics Unit protocol includes:}

Thorough history taking according to the protocol of language assessment of Kotby et al., 1995, including full personal, family, medical, and developmental history with special emphasis on age at discovery of hearing impairment, age at start of use of unilateral or bilateral hearing aids, and means of communication.

Patient examination: general examination, neurological examination, and vocal tract and ENT examination. The Stanford Binet Intelligence Test (fourth edition) (Thorndike et al., 1986) to assess 
mental ability. The Standardized Arabic Language Test to determine the percentage of total language score.

2) Nottingham Early Assessment Package (NEAP) (Nikolopoulos et al., 2005): NEAP uses video analyses, observational profiles, interviews, and questionnaires. Some of the measures can be used from early infancy right through to adulthood, providing continuity and the basis for long-term comparisons in the various areas of development. It focuses on a child's strengths as well as weaknesses, and has been shown to be time effective, user friendly, informative, reliable and valid assessment for young deaf children with cochlear implants. It includes:

\section{- Communication and language development:}

i. Tait Video Analysis: preverbal communication skills.

ii. Preschool Profile of Early Communication Skills (PPECS): pragmatic skills .

iii. Profile of Actual Linguistic Skills (PALS): development of spoken language .

iv. Preschool Language Scale (PLS): developmental language pre-cursors.

v. Story/Narrative Assessment Procedure (SNAP Dragons: (story/narrative development.

\section{- Auditory perception:}

i. Meaningful Auditory Integration Scale (MAIS): measuring everyday use of sound and hearing aid or implant.

ii. Listening Progress Profile (LIP): measuring early listening skills.

iii. Categories of Auditory Performance (CAP): measuring auditory performance in everyday life.

\section{- Speech production :}

i. The Speech Intelligibility Rating (SIR): a profile of speech intelligibility.

ii. The Profile of Actual Speech Skills (PASS): early speech production video analysis .

3) EARS (Evaluation of Auditory Responses to Speech) (EsserLeyding, 2012):

EARS is currently one of the most used in Europe. Since it was presented; it was adapted to more than 20 languages, allowing for the comparison of performance between children from different languages and cultures. This instrument tool is currently aimed to: (i) assess the development of hearing perception in children with severe to profound hearing loss, provided with cochlear implants; (ii) provide support in rehabilitation and (iii) be used as a long-term assessment tool for children provided with a cochlear implant. Its target population includes children with severe to profound hearing loss between 3 and 10 years of age .

The EARS battery of tests consists of the following:

○ LiP - Listening Progress Profile (Archbold S., 1994) Monitoring of auditory development changes in hearing-impaired children

○ MTP - Monosyllabic-TrocheePolysyllabic

(Erber \&

Alencewicz, 1976)

- Monosyllable Closed- Set Test (Schneider et al., 1996)

- Closed-Set Sentence Test (Tyler \& Holstad, 1987)

○ Monosyllable Open-Set Test (Schneider et al., 1995)

$\circ$ GASP - Glendonald Auditory Screening Procedure (Erber, 1982)

- COT - Common Objects Token Test (Anderson et al., 2005) 
- MAIS - Meaningful Auditory Integration Scale (Robbins et al., 1991) Hearing ability and its use in natural environments

- MUSS - Meaningful Use of Speech Scale (Robbins \& Osberger, 1990)

- Vocal control, speech use and communicative strategies

II-Design of our protocol of management of HI children includes :

A. Elementary diagnostic procedures: Thorough history taking including full personal, family, medical, and developmental history with special emphasis on age at discovery of hearing impairment, age at commencement of use of hearing aids, and means of communication.

Patient examination: general examination, neurological examination, and vocal tract and ENT examination .

\section{B. Clinical diagnostic aids:}

i. The Stanford Binet Intelligence Test fifth edition (nonverbal part) (Thorndike et al., 1986) to assess mental ability.

ii. The intelligence quotient was determined as a percentage ratio of mental age to chronological age.

iii. The Standardized Arabic Language test to determine the percentage of total language score .

iv. Evaluation of Attention Deficit Hyperactivity Disorder by Attention Deficit Hyperactivity Disorder Test (ADHDT)

C. Scheduled clinic follow-ups at our phoniatrics unit were done at 3 months, 6months, 9months, 1year, 1.5 years, 2 years, 2.5 years, 3 years then every year for 10 years after implant .

\section{III- Validity and specificity:}

After the experts reviewing the protocol there were some points

\section{A. Content validity :}

1. There were frequent revisions of the protocol by the phoniatricans for some items in the patient interview like adding the effect of $\mathrm{HI}$ on learning, social, psychological aspects of the child and family .

2. There were some modifications to develop a follow up sheet for our patients including number of hours of parent involvement in language stimulation at home, family subjective evaluation of active and passive vocabulary if the child is shy or not responding .

3. Using video recording to save the evaluation and analyze child parent interaction, also future use of parent questionnaires in cases of uncooperative shy children.

4. Design of the protocol as in appendix I, II, III.

\section{B. Test - Retest:}

The study was conducted on a series of 130 patients with CI at Sohag university hospital. 79 males, 51 females, mean age at implantation $46.4+12.3$ months and the mean age at the 1.5 year follow up evaluation was $70.5+8.2$ months. All cases were unilaterally implanted, 116 cases were left ear implanted and 14 cases were right ear implanted.

Assessment was done by applying the sheet before and after implantation and sessions and during follow up intervals. Mean and standard deviation of auditory, receptive and expressive scores was calculated at Table 1.

Using Friedman test for nonparametric data, the increase in the auditory, receptive and expressive scores before and after implantation and through each follow up interval after 3 months, 6months, 9months, 1year, 1.5 years are highly significant; $P$ value $\geq 0.001$. 
Table1: Differences in Mean \pm SD and significance of auditory, receptive and expressive scores before and after implantation and through follow up intervals

\begin{tabular}{|c|c|c|c|c|c|c|}
\hline Mean \pm SD & Preoperative & $\mathbf{3 m}$ & $\mathbf{6 m}$ & $\mathbf{9 m}$ & $\mathbf{1 y r}$ & $\mathbf{1 . 5} \mathbf{y}$ \\
\hline Auditory scores & $0.12 \pm 0.67$ & $5.36 \pm 3.64$ & $7.3 \pm 4.15$ & $10.01 \pm 5.39$ & $12.54 \pm 6.54$ & $15.32 \pm 7.44$ \\
\hline Receptive scores & $0.22 \pm 0.95$ & $1.13 \pm 2.97$ & $3.18 \pm 6.1$ & $6.8 \pm 10.59$ & $11.29 \pm 13.73$ & $19.69 \pm 18.83$ \\
\hline Expressive scores & $0.15 \pm 0.81$ & $0.33 \pm 1.29$ & $1.17 \pm 2.9$ & $3.92 \pm 7.64$ & $7.18 \pm 10.9$ & $13.86 \pm 15.48$ \\
\hline
\end{tabular}

* P-value was calculated by Friedman test and is highly significant

\section{Discussion :}

To develop our protocol of assessment we chose to adapt same item of assessment of three main protocols Ain Shams Phoniatrics Unit, Nottingham Early Assessment Package, EARS protocols. As these protocols are the most suitable for application with our facilities, they have nearly the same structure (receptive, expressive, and auditory skills) and they are the most commonly protocols used worldwide. The developed protocol revised by 3 phoniatricians with experiences ranging from 7 years up to 25 years.

\section{Sohag Phoniatric unit protocol has the following advantages:}

During examination SUH protocol added evaluation of auditory skills of the patient as auditory detection, discrimination and localization. There was significant correlation between auditory score and both receptive and expressive scores (El-Adawy et al., 2019). Nunn et al., 2019 stated that increasing $\mathrm{T}$ levels when programming a CI has the effect of improving the audibility of soft intensity sound by increasing corresponding electrical current stimulation. SUH protocol added evaluation of hours of parent participation at home with the child. Percy-Smith et al., 2012 suggested that parents play the most important role in infants' language development and habilitation program must involve parents in order to secure positive outcomes.

SUH protocol added evaluation of regularity of rehabilitation sessions. Zohdi et al., 2014 stated that patients who regularly attend speech rehabilitation are associated with lower (i.e., better) auditory thresholds and higher receptive language age.

The protocol of SUH added the postoperative data and follow up data of the patient including age at implantation Liu et al.,2019 found that the younger the age at implantation, the better is the effect of cochlear implant on the outcomes. Earlier implantation helps patients restore hearing and receive speech training earlier, protocol of SUH added the side of implantation as Children with rightear implants appeared to have an advantage over children with left-ear implants: they tended to produce more words, more different words, and longer utterances (Henkin et al., 2008).

Protocol of SUH added the evaluation of hyperactivity. There were significant relations between auditory, receptive and expressive scores and grade 0 hyperactivity in our study. Protocol of SUH added the evaluation of inattention as Attention to the language-specific properties lead to successful word recognition and representation (Werker \& Curtin, 2005). These points weren't included at protocol of Ain Shams Phoniatrics Unit.

Sohag phoniatric protocol has some advantages like involving thorough 
history taking, including full personal, family, medical, and developmental history with special emphasis on age at discovery of hearing impairment, Saki et al., 2018 noted that the early diagnosis and management of hearing loss significantly influences the rate of developmental skills in hearing impaired children. Our protocol added the age at start of use of hearing aids as Very early use of HAs in children with residual hearing provides auditory access to language until the child receives an implant. Therefore, their experience with HAs before implantation may provide them with advantages of early auditory stimulation than more profoundly deaf HA users (Eisenberg et al. 2006). We added the means of communication either verbal or gestures or signing so it is suitable for nonverbal children. Abou-Elsaad et al., (2016) reported that children with prelingual deafness who use oral communication achieve higher levels of speech perception, speech production, and/or language skills compared with their deaf peers who use total communication; that is the combined use of sign and spoken language. Also, our protocol includes patient examination: general examination, neurological examination, and vocal tract and ENT examination to detect any syndromic cases associated with hearing impairment. These points weren't included at NEAP.

Sohag phoniatric protocol has some advantages in detailed examination of receptive and expressive language and hyperactivity and inattention, psychological status of the child using Stanford-Binet intelligence scale Geers (2002) stated that the most important characteristic of the child to benefit from a cochlear implant is good native intelligence as quantified by a nonverbal measure. These points weren't included at EARS.
Sohag protocol of assessment of CI patients is effective in preoperative assessment and postoperative follow up for evaluating the efficacy of rehabilitation program and defective scales to focus on them at the rehabilitation sessions. That was proved by the statistically significant improvement of patient's auditory and linguistic skills.

\section{Conclusion:}

Applying the protocol of assessment of CI patients of Sohag phoniatric unit leads to improvement in the results after management of patients and this was proved by comparing the results of the patients before and after operation and sessions and through follow up intervals, this may be due to good evaluation of the auditory, receptive and expressive skills of the patients.

Conflict of interest: The authors declare no competing interests.

\section{Reference:}

1. Abdollahi, F.Z., Ahmadi, T., Joulaie, M. \& Darouie, A. Cochlear Implant in Children: Global Journal of Otolaryngology;2017 8(5): 11-16.

2. Abou-Elsaad T, Baz H, Allatif GA, Afsah O, Amer A, Marzouk N. Mansoura University habilitation outcome of prelingual cochlearimplanted children: 5 years of experience. The Egyptian Journal of Otolaryngology. $2016 \mathrm{Jul}$ 1;32(3):222.

3. Anderson I, Martin J, Costa A, Jamieson L, Bailey E, Plant G, Pitterl M. Validation of the Common Objects Token (COT) Test for children with cochlear implants. Deafness \& Education International. 2005 Sep;7(3):154-70.

4. Archbold S. Monitoring progress in children at the pre-verbal stage. Cochlear implants for young children. In: B McCormick, S Archbold, S Sheppard Eds. Cochlear Implants for 
Young Children. London: Whurr: 1994,197-213.

5. Doll E. Vineland sosial maturity scale. Minnesota: Amerika Guidance Service; 1965

6. Eisenberg LS, Johnson KC, Martinez AS, Cokely CG, Tobey EA, Quittner AL, Fink NE, Wang NY, Niparko JK. Speech recognition at 1-year follow-up in the childhood development after cochlear implantation study: methods and preliminary findings. Audiology and Neurotology. 2006;11(4):259-68.

7. Eladawy, A.A.N., Emam, A.M., Mostafa, E.M. \& Awad, H.E. Prelingual Cochlear Implantation Program In Sohag University Hospital "Phoniatric Overview" [Unpublished Thesis]. Egypt, Sohag: Sohag university medical school;2019.

8. El-Sady, S.R., El-Shoubary, A.M., Hafez, G.N. \& Abo-Hasseba, A.M. Translated, modified and standardized Preschool Language Scale [Unpublished Thesis]. 4th ed. Cairo: Ain Shams Medical School; 2011.

9. Erber NP, Alencewicz CM. Audiologic evaluation of deaf children. Journal of Speech and Hearing Disorders. 1976 May;41(2):256-67.

10.Erber NP. Auditory training. Alex Graham Bell Assn for Deaf; 1982.

11.Esser-Leyding B, Anderson I. EARS® (Evaluation of Auditory Responses to Speech): An internationally validated assessment tool for children provided with cochlear implants. ORL. 2012;74(1):42-51.

12.Faraj, S. Stanford-Binet Intelligence Scales (SB5), Fifth Edition. Cairo: the Anglo Egyptian Bookshop;2010.

13.Geers AE. Factors affecting the development of speech, language, and literacy in children with early cochlear implantation. Language, Speech, and Hearing Services in Schools. 2002,33(3): 172-183.

14.Henkin Y, Taitelbaum-Swead R, Hildesheimer M, Migirov L, Kronenberg J, Kishon-Rabin L. Is there a right cochlear implant advantage? Otology \& Neurotology. 2008 Jun $1 ; 29(4): 489-94$.

15.Gilliam JE. AttentionDeficit/Hyperactivity Disorder Test: A
Method for Identifying Individuals with ADHD: Examiner's Manual. Proed; 1995.

16.Jones CB. Sourcebook for children with attention deficit disorder: a management guide for early childhood professionals and parents. Communication Skill Builders/Therapy Skill Builders; 1991.

17.Kempler, D. Neurocognitive Disorders in Aging. Sage Publications. 2005, pp. 92-105. ISBN 0-7619-2163-X.

18. Kotby MN, Khairy A, Barakah M, Rifaie N, El Shobary A. Language testing of Arabic speaking children. MN Kotby ed. InProceeding of the XVIII World Congress of the International Association of Logopedics and Phoniatric. Cairo, Egypt: Secretariat of XXIII World Congress of the International Association of Logopedics and Phoniatrics (IALP) 1995 (pp. 263-266).

19.Liu S, Wang F, Chen P, Zuo N, Wu C, Ma J, Huang J, Wang C. Assessment of outcomes of hearing and speech rehabilitation in children with cochlear implantation. Journal of Otology. 2019 Feb 5,14 (2): 57-62.

20.Nikolopoulos TP, Archbold SM, Gregory S. Young deaf children with hearing aids or cochlear implants: early assessment package for monitoring progress. International journal of pediatric otorhinolaryngology. 2005 Feb 1;69(2):175-86.

21.Nunn TB, Jiang D, Green T, Boyle PJ, Vickers DA. A systematic review of the impact of adjusting input dynamic range (IDR), electrical threshold (T) level and rate of stimulation on speech perception ability in cochlear implant users. International journal of audiology. 2019 Jun 3;58(6):317-25

22.Pell MD. Fundamental frequency encoding of linguistic and emotional prosody by right hemisphere-damaged speakers. Brain and language. 1999 Sep 1;69(2):161-92.

23.Percy-Smith L, Busch GW, Sandahl M, Nissen L, Josvassen JL, Bille M, Lange T, Cayé-Thomasen P. Significant regional differences in Denmark in outcome after cochlear implants in 
children. Dan Med J. 2012 May 1;59(5): A4435.

24.Robbins AM, Renshaw JJ, Berry SW. Evaluating meaningful auditory integration in profoundly hearingimpaired children. The American journal of otology. 1991; 12:144-50.

25.Robbins AM, Osberger MJ. Meaningful use of speech scale (MUSS). Indianopolis: Indiana University School of Medicine. 1990.

26.Saki N, Abshirini H, Bayat A, Nikakhlagh S, Fahimi A, Heidari M, Riahi M. Factors Affecting Age of Diagnosis and Rehabilitation Intervention in Children Receiving Cochlear Implant. The International Tinnitus Journal. 2018 Dec 27;22(2):123-7.

27.Schneider, A., Leyrer, M., Pilkington, M.C. \& Allum, D. Monosyllable OpenSet Test. Innsbruck: MED-EL: (1995).

28.Schneider, A., Leyrer, M., Pilkington, M.C. \& Allum, D. Monosyllable Closed- Set Test. Innsbruck: MED-EL: (1996).

29.Thorndike RL, Hagen EP, Sattler JM. The Stanford-Binet Intelligence Scale:
Guide for Administration and Scoring. Chicago: Riverside. 1986.

30.Tyler RS, Holstad BA. A closed-set speech perception test for hearingimpaired children. Department of Otolaryngology. Head and Neck Surgery, University of Iowa, Iowa City, IA. 1987.

31.Vlastarakos PV, Proikas K, Papacharalampous G, Exadaktylou I, Mochloulis G, Nikolopoulos TP. Cochlear implantation under the first year of age-The outcomes. A critical systematic review and meta-analysis. International Journal of Pediatric Otorhinolaryngology. $2010 \quad$ Feb 1;74(2):119-26.

32.Werker JF, Curtin S. PRIMIR: A developmental framework of infant speech processing. Language learning and development. 2005 Apr 1;1(2):197234.

33.Zohdi I, AbdelMessih MW, El Shennawy AM, Ashour BM, Kandil GE. Statistical analysis of various factors affecting the results of cochlear implantation. The Journal of International Advanced Otology. 2014 May 1;10(2):118. 


\section{Appendix I}

\section{Protocol of assessment of CI children at SUH}

\section{1- Before CI operation (during family and patient interview)}

- Detect the Degree of family motivation for language therapy

- Whether family expectations are realistic or not

- Correct the unrealistic family expectations in the interview

- Tell the family about the nature of the implant and emphasize on the care that must be given to the apparatus and the child and the difference between normal hearing and hearing electrical signals by the CI that needs time and effort from the caregivers and therapy provider

- Write down the decision at the sheet either yes or no or any concern is taken and date of the committee and whether the case had the agreement of health insurance or not, this help us for planning the therapy and follow up.

- The importance of wearing the hearing aid regularly all day and taking preoperative therapy for at least 3-6 months even if there is poor response to ensure compliance and better results at postoperative habilitation

- There is a database established for all cases including their phone numbers and address and there is continuous data recording for every case.

\section{2- At the day of the CI operation}

- Brief idea about hearing using CI

- Brief idea about normal auditory detection and discrimination

- Language development in $\mathrm{HI}$ and $\mathrm{CI}$

- The importance of regular follow up in our unit if the family could not afford to come for therapy

- Follow up schedule in our unit as soon as the first programming of the device takes place for start of therapy

- The importance of parents' involvement in the auditory habilitation of their children

- Steps of rehabilitation

- Take the parents' signature on consent of follow up schedule at our unit and if they didn't come, they take the whole responsibility

3-At the first session: immediately after first programming

- Counseling as regard the best place and the best provider of sessions available for the patient (if the patient is taking therapy outside our unit) with emphasis on the importance of regular follow up at our unit

- Thorough counseling of the family as regard auditory and language habilitation of the child, tone changing, using environmental sounds and spontaneous events to enriches 
the child language with the suitable rewarding of any language improvement made by the child.

- The importance of regular use of the device and keep it away from water or damage and checking it continuously to make sure that it is working

- Start with the child at home with sound detection and sound discrimination of domestic devices as telephone ring or door knocking

\section{4-At the follow up setting}

- Corrective feedback about the way of dealing with the child and the sessions and proceed in semantics, syntax, phonology, pragmatics according to the child's age.

- Cases are re-evaluated and re-counseled and re-motivated for therapy every 3 months of the first-year post implantation and then every 6 months afterwards.

- Re-evaluate previous concerns as hyperactivity or lack of family motivation and correct them.

- Missed cases are called by phone to complete their follow up schedule. If the phone isn't reachable, letters are sent to their address and they sign it on arrival to make sure they get it. 


\section{Appendix II \\ Assessment protocol}

\section{Elementary diagnostic procedure:}

\section{1- Parents interview:}

- Name of the child. - Age of the child. - Sex - Residence

- Father's job - Mother's job - Consanguinity

\section{2- Prenatal history:}

Fever Infection

Medication.......

Trauma...... Irradiation

Operations

Smoking......

\section{3- Perinatal and postnatal history:}

- Type of delivery - Place of delivery - Term

- weight

- 1st Cry.

- Cyanosis/Oxygen supply....

- Jaundice...

Level of bilirubin

Measures taken

- Fits

\section{4- Milestones of the child:}

Sitting

$1^{\text {st }}$ word

Self-feeding
Walking

$1^{\text {st }}$ sentence

Self dressing

\section{Toilet control}

\section{5- History of present illness:}

- Duration of hearing loss before CI.

- Whether the child received language therapy before CI, and its duration.

- Age at implantation at time of operation.

- Type and duration of using hearing devices.

- Duration of rehabilitation and regularity in attending the habilitating sessions.

\section{6-Assessment of Current Communicative Abilities:}

- Eye contact - Eye hand coordination

- Response to the examiner: (obey simple order, motor imitation, verbal imitation)

- Communication mean: verbal, gestures, signing

- Subjective evaluation of

a- Inattention: It is evaluated subjectively according to age

- Level 1 (0-1 Year). Extreme distractibility.

- Level 2 (1-2 Years). Single channeled attention. Cannot tolerate (ignores) verbal or visual intervention from an adult.

- Level 3 (2-3 Years). Still single channeled. But, with an adult's help, they can shift their full attention to the speaker and then back to the game. 
- Level 4 (3-4 Years). Still alternates full attention between the speaker and the task. Now does this spontaneously, without the adult needing to focus and re-focus that attention.

- Level 5 (4-5 Years). Attention is now two channeled. The child understands verbal instructions related to the task without interrupting the activity to look at the speaker.

- Level 6 (5-6 Years). Auditory, visual and manipulatory channels are fully integrated. Attention is well established and maintained. (Jones, 1991)

b- Hyperactivity: It is evaluated and graded subjectively with a 5-grade scale. It is created $\begin{array}{lllllll}\text { in this study and used as follows: } & 0 & 1 & 2 & 3 & 4\end{array}$ $0=$ no hyperactivity

1 = fidgets with hands or feet

$2=$ squirms and climbs in seat

$3=$ leaves seat

$4=$ runs about or climbs excessively

\section{Quasi-objective assessment of child's auditory abilities:}

Score from 0 to 2 : $\quad 0=$ No response $\quad 1=$ Inconsistent $\quad 2=$ Consistent

Sound detection: Soft sound, Loud sound.

Respond to his name.

Sound localization.

Detection of 6 Ling's sounds.

Discriminate 6 Ling's sounds.

Discriminate Long / Short sound.

Discriminate single / repeated.

Discriminate male / female voice.

Discriminate Continuous / Interrupted sound.

Discriminate High / Low pitched sound.

Discriminate Soft / Loud sound.

Discrimination between 2 musical instruments.

Identify 10 environmental sounds.

\section{Inner language:}

(object permeance, object constancy, causality, reversibility)

Passive vocabulary: Ten semantic groups, six pictures per each group will be used (body parts, animals, transportation, clothes, vegetables, fruits, kitchen tools, furniture, colors, shapes) 


\section{Semantics:}

Active vocabulary

Size of vocabulary

a- At the word level: at both the receptive and expressive level

Synonyms, Antonyms, Hyponyms, Analogy

b- At the sentence level: at both the receptive and expressive level

Using: sentence formulation cards, Sequencing cards, Stories.

Syntax: Good Fair Poor

Phonology:

Segmental level:

$$
\begin{aligned}
& \text { Single phonological error } \\
& \text { Multiple phonological errors: Consistent }
\end{aligned}
$$
Inconsistent

Multiple phonological processes

Supra segmental level:

Pitch: (Average- High- Low)

Loudness: (Average-Loud-Soft)

Pragmatics: Quasi- objective assessment of pragmatics during conversation in 5 items (Present/ Not present) as follows:

- Topic (e.g. maintenance),

- Turn taking (e.g. interrupting)

- Paralinguistic characteristics (e.g. vocal intensity)

- Nonverbal characteristics (e.g. physical position, eye gaze),

- Narrative cohesion

\section{Auditory perceptual assessment of speech and voice in verbal children:}

a) Speech intelligibility ( $0=$ unintelligible, $1=$ severe unintelligible, $2=$ Moderate unintelligible, $3=$ intelligible)

b) Resonance: hyper/hyponasality ( $0=$ Normal, $1=$ mild, $2=$ moderate, $3=$ severe)

c)Dysprosody

d)Dysphonia

\section{II-Clinical diagnostic aids:}

1- Language assessment using the Arabic translation of the preschool language scale 4 (PLS4) will be used in verbal children (El Sady et al.,2011).

2- Psychological status of the child:

- Intellectual assessment using Arabic version of Stanford-Binet Intelligence scale $5^{\text {th }}$ edition (Faraj,2010).

- Social age using Vineland Social Maturity Scale (Doll, 1965). 
3- Evaluation of Attention Deficit Hyperactivity Disorder by Attention Deficit Hyperactivity Disorder Test (ADHDT) (Gilliam, 1995).

4- Audiological evaluation:

- Threshold level for CI.

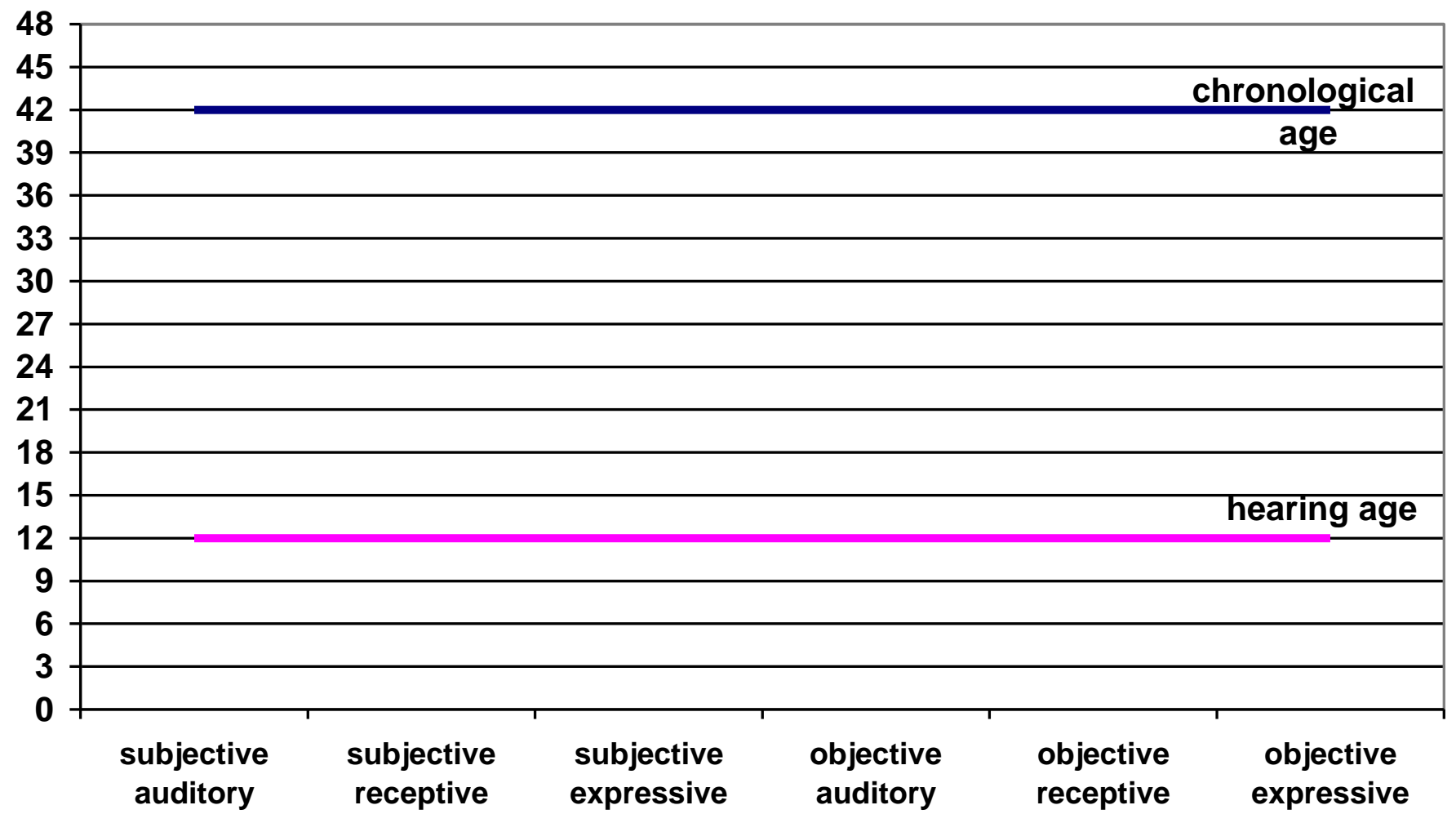

Evaluation chart 


\section{Appendix III}

\section{Follow up sheet of CI}

Name

Address in details

Tel. number:

Date of birth:

Date of operation:

Date of first fitting:

Date of starting sessions:

Reimplant (if present):

Date of reimplant:

First fitting after reimplant:

Starting Sessions after reimplant

Accidents or broken device (if present):

Type of accident

Date

Period at which the device was broken

\begin{tabular}{|l|l|l|l|}
\hline & First visit & Second visit & Third visit \\
\hline Date & & & \\
\hline Follow up & & & \\
\hline Number of sessions & & & \\
\hline Place of rehabilitation & & & \\
\hline Regularity & & & \\
\hline Parent participation $\mathrm{hr} / \mathrm{w}$ & & & \\
\hline
\end{tabular}

\section{I- Family subjective evaluation:}

\begin{tabular}{|l|l|l|l|}
\hline & First visit & Second visit & Third visit \\
\hline Hearing & & & \\
\hline Hyperactivity & & & \\
\hline Communication mean & & & \\
\hline Passive vocabulary & & & \\
\hline Active vocabulary & & & \\
\hline
\end{tabular}


II- Assessment of Current Communicative Abilities:

\begin{tabular}{|l|l|l|l|}
\hline & First visit & Second visit & Third visit \\
\hline Eye contact & & & \\
\hline Eye hand coordination & & & \\
\hline Response to examiner & & & \\
\hline Communication mean & & & \\
\hline Inattention (1-6) & & & \\
\hline Hyperactivity (0-4) & & & \\
\hline
\end{tabular}

\section{Quasi-objective assessment of child's auditory abilities:}

Score from 0 to $2,0=$ No response $1=$ Inconsistent $2=$ Consistent

\begin{tabular}{|l|l|l|l|}
\hline & First visit & Second visit & Third visit \\
\hline Detection of soft sound & & & \\
\hline Detection of loud sound & & & \\
\hline Respond to his name & & & \\
\hline Sound localization & & & \\
\hline Detection of 6 Ling's sounds & & & \\
\hline Discriminate 6 Ling's sounds & & & \\
\hline Discriminate Long / Short sound & & & \\
\hline Discriminate single / repeated & & & \\
\hline Discriminate male / female voice & & & \\
\hline Discriminate Continuous / Interrupted sound & & & \\
\hline Discriminate High / Low pitched sound & & & \\
\hline Discriminate Soft / Loud sound & & & \\
\hline Discrimination between 2 musical instruments & & & \\
\hline Identify 10 environmental sounds & & & \\
\hline
\end{tabular}




\section{Inner language:}

Passive vocabulary: Ten semantic groups, six pictures per each group will be used

\begin{tabular}{|l|r|r|r|r|r|r|}
\hline & \multicolumn{2}{l}{ First visit } & \multicolumn{2}{l|}{ Second visit } & \multicolumn{2}{l|}{ Third visit } \\
\hline & receptive & expressive & receptive & expressive & receptive & expressive \\
\hline Body parts & $/ 6$ & $/ 6$ & $/ 6$ & $/ 6$ & $/ 6$ & $/ 6$ \\
\hline Animals & $/ 6$ & $/ 6$ & $/ 6$ & $/ 6$ & $/ 6$ & $/ 6$ \\
\hline Transportation & $/ 6$ & $/ 6$ & $/ 6$ & $/ 6$ & $/ 6$ & $/ 6$ \\
\hline Clothes & $/ 6$ & $/ 6$ & $/ 6$ & $/ 6$ & $/ 6$ & $/ 6$ \\
\hline Vegetables & $/ 6$ & $/ 6$ & $/ 6$ & $/ 6$ & $/ 6$ & $/ 6$ \\
\hline Fruits & $/ 6$ & $/ 6$ & $/ 6$ & $/ 6$ & $/ 6$ & $/ 6$ \\
\hline Kitchen tools & $/ 6$ & $/ 6$ & $/ 6$ & $/ 6$ & $/ 6$ & $/ 6$ \\
\hline Furniture & $/ 6$ & $/ 6$ & $/ 6$ & $/ 6$ & $/ 6$ & $/ 6$ \\
\hline Colors & $/ 6$ & $/ 6$ & $/ 6$ & $/ 6$ & $/ 6$ & $/ 6$ \\
\hline Shapes & $/ 6$ & $/ 6$ & $/ 6$ & $/ 6$ & $/ 6$ & $/ 6$ \\
\hline OSD & & & & & & \\
\hline
\end{tabular}

Semantics:

\begin{tabular}{|r|r|r|r|}
\hline & First visit & Second visit & Third visit \\
\hline Size of vocabulary & & & \\
\hline Length of sentence & & & \\
\hline
\end{tabular}

Syntax: score from 0 to $2,0=$ no response $1=$ inconsistent $2=$ consistent

\begin{tabular}{|c|c|c|c|c|c|c|}
\hline & \multicolumn{2}{|l|}{ First visit } & \multicolumn{2}{|c|}{ Second visit } & \multicolumn{2}{|l|}{ Third visit } \\
\hline & Receptive & Expressive & Receptive & Expressive & Receptive & Expressive \\
\hline Place indicator & & & & & & \\
\hline Time indicator & & & & & & \\
\hline Pronouns & & & & & & \\
\hline Adjectives & & & & & & \\
\hline Opposites & & & & & & \\
\hline Negation & & & & & & \\
\hline Regular pleural & & & & & & \\
\hline Comparatives & & & & & & \\
\hline Superlatives & & & & & & \\
\hline Counting & & & & & & \\
\hline Possession & & & & & & \\
\hline Adverbs & & & & & & \\
\hline Verb tense past & & & & & & \\
\hline
\end{tabular}




\begin{tabular}{|l|l|l|l|l|l|l|}
\hline $\begin{array}{l}\text { Verb tense } \\
\text { present }\end{array}$ & & & & & & \\
\hline Verb tense future & & & & & & \\
\hline Passive tense & & & & & & \\
\hline Irregular pleural & & & & & & \\
\hline
\end{tabular}

Phonology:

Segmental level:

\begin{tabular}{|l|l|l|l|}
\hline & First visit & Second visit & Third visit \\
\hline Single phonological error & & & \\
\hline Multiple phonological errors & & & \\
\hline Multiple phonological processes & & & \\
\hline
\end{tabular}

Supra segmental level:

\begin{tabular}{|l|l|l|l|}
\hline & First visit & Second visit & Third visit \\
\hline Pitch: (average- high- low) & & & \\
\hline Loudness: (average-loud-soft) & & & \\
\hline
\end{tabular}

Pragmatics: Quasi- objective assessment of pragmatics during conversation in 5 items (present/ not present) as follows:

\begin{tabular}{|l|l|l|l|}
\hline & First visit & Second visit & Third visit \\
\hline Topic maintenance & & & \\
\hline Turn taking (Number of turns) & & & \\
\hline Paralinguistic characteristics (vocal intensity) & & & \\
\hline Nonverbal characteristics (physical position, eye gaze) & & & \\
\hline Narrative cohesion & & & \\
\hline
\end{tabular}

Auditory perceptual assessment of speech and voice in verbal children:

\begin{tabular}{|l|l|l|l|}
\hline & First visit & Second visit & Third visit \\
\hline Speech intelligibility & & & \\
\hline Resonance & & & \\
\hline Dysprosody (emotional/linguistic/both) & & & \\
\hline Dysphonia (grade) & & & \\
\hline
\end{tabular}

\section{III-Clinical diagnostic aids:}

5- Threshold level for $\mathrm{CI}$

\begin{tabular}{|r|r|r|r|}
\hline & First visit & Second visit & Third visit \\
\hline SDT & & & \\
\hline
\end{tabular}


6- Language assessment using the preschool language scale 4 (PLS4)

7- Psychological status of the child:

- Arabic version of Stanford-Binet Intelligence scale $5^{\text {th }}$ edition

- Social age using Vineland Social Maturity Scale

8- Attention Deficit Hyperactivity Disorder Test (ADHDT)

\section{Guide for CI follow up sheet}

- Response to examiner: Poor Fair Good

- Communication mean mainly by verbal, gestures, signing

- Subjective evaluation of

$\begin{array}{lllllll}\text { a-: Inattention } & 1 & 2 & 3 & 4 & 5 & 6 \\ \text { b-: Hyperactivity } & 0 & 1 & 2 & 3 & 4 & \end{array}$

a- Inattention: It is evaluated subjectively according to age

- Level 1 (0-1 Year). Extreme distractibility.

- Level 2 (1-2 Years). Single channeled attention. Cannot tolerate (ignores) verbal or visual intervention from an adult.

- Level 3 (2-3 Years). Still single channeled. But, with an adult's help, they can shift their full attention to the speaker and then back to the game.

- Level 4 (3-4 Years). Still alternates full attention between the speaker and the task. Now does this spontaneously, without the adult needing to focus and re-focus that attention.

- Level 5 (4-5 Years). Attention is now two channeled. The child understands verbal instructions related to the task without interrupting the activity to look at the speaker.

- Level 6 (5-6 Years). Auditory, visual and manipulatory channels are fully integrated. Attention is well established and maintained.

b- Hyperactivity: It is evaluated and graded subjectively with a 5-grade scale: $\quad 0$

$0=$ no hyperactivity

$1=$ fidgets with hands or feet

$2=$ squirms and climbs in seat

$3=$ leaves seat

4 = runs about or climbs excessively 
Quasi-objective assessment of child's auditory abilities: score from 0 to 2, $0=$ no response $1=$ inconsistent $2=$ consistent, except identify 10 environmental sounds score from 0 to $3,(0=25 \%, 1=50 \%, 2=75 \%, 3=100 \%)$

\section{Phonology:}

Segmental level:

Single phonological error ----/Sound/------ $\quad$ (Initial - Middle - Final)

Multiple phonological errors: Consistent--/Sound/-----(Initial - Middle - Final) Inconsistent---/Sound/-----(Initial- Middle -Final)

Multiple phonological processes---Types

Supra segmental level:

$$
\begin{aligned}
& \text { Pitch: (Average- High- Low) } \\
& \text { Loudness: (Average-Loud-Soft) }
\end{aligned}
$$

\section{Auditory perceptual assessment of speech and voice in verbal children:}

a) Speech intelligibility ( $0=$ unintelligible, $1=$ severe unintelligible,

$$
2=\text { moderate unintelligible, } 3=\text { intelligible) }
$$

b) Resonance: hyper/hyponasality ( $0=$ Normal, $1=$ mild, $2=$ moderate, $3=$ severe)

c)Dysprosody:

There are two types of dysprosody, linguistic and emotional, that each present with slightly different symptoms. It is possible that one can present with both forms of dysprosody.

\# Emotional: A person suffering from dysprosody would not be able to accurately convey emotion vocally, such as through pitch or melody, or make any conclusion about another person's feeling through his speech (Kempler, 2005).

\# Linguistic: prosody is responsible for verbal variations in interrogative versus declarative statements and serious versus sarcastic remarks. Linguistic dysprosody refers to the diminished ability to verbally convey aspects of sentence structure, such as placing stress on certain words for emphasis or using patterns of intonation to reveal the structure or intention of an utterance. For example, individuals with linguistic dysprosody may have difficulty distinguishing the production of interrogative and declarative sentences, switching or leaving out the expected rising and falling shift, respectively. Thus, linguistic dysprosody alters an individual's vocal identity and impairs verbal communication (Pell, 1999).

d)Dysphonia 